date. Data have been collected on disease phenotype, treatment, adverse events and treatment response.

Aim To describe the prevalence of adverse events related to thiopurine exposure among the IBD Bioresource cohort

Methods A descriptive, retrospective analysis of the IBD BioResource database has been performed to determine the incidence of short and long-term adverse events related to the use of thiopurines in the treatment of inflammatory bowel disease. All patients who have had exposure to thiopurine therapy (azathioprine or 6-mercaptopurine) were included.

Results 10092 (57.8\%) patients within the IBD BioResource cohort have had some exposure to thiopurine therapy during their disease course, either as monotherapy or in combination with anti-TNF.

9480 patients (94.0\%) have been treated with azathioprine (AZA) and 2335 patients (23.1\%) have been treated with 6mercaptopurine (6 MP). Of the 9480 patients who have been treated with azathioprine, 4167 patients (44.0\%) remain on this therapy. 2369 patients $(24.9 \%)$ ceased azathioprine due to adverse events.

1723 of the $2335(73.8 \%)$ patients treated with $6 \mathrm{MP}$ had previously been treated with AZA and been intolerant. 684 patients $(29.3 \%)$ ceased $6 \mathrm{MP}$ due to adverse events.

The most commonly reported adverse events were nausea and vomiting $(9.6 \%)$, followed by deranged liver function tests (5.1\%), non-specified patient intolerance (2.4\%), flu like symptoms $(2.3 \%)$ and abdominal pain $(2.3 \%)$. The incidence of clinically serious side effects was low. Pancreatitis was reported in $2.2 \%$ of patients; and leukopenia (total WCC $<3$ or neutrophil count $<2$ ) was seen in $379(3.7 \%) .83(0.8 \%)$ patients developed lymphoma after a mean of 2.9 years on thiopurine treatment. 27/83 were also on anti-TNF.

Conclusion We report a large, real world series of patients with IBD treated with azathioprine or $6 \mathrm{MP}$. Thiopurines were ceased due to side effects in $25.1 \%$ of patients overall. The incidence of adverse events with $6 \mathrm{MP}$ was only modestly higher than in those treated with azathioprine, despite 73.8\% having been previously treated with azathioprine. Serious clinical adverse events related to thiopurine exposure were observed but at low frequency.

\section{PTH-095 DECISION DRIVERS IN CROHN'S DISEASE MANAGEMENT WITH BIOLOGICS IN THE NHS: A NATIONAL CONSENSUS VIEW}

${ }^{1}$ Sami Hoque*, ${ }^{2}$ Sue Jones, ${ }^{3}$ Simon Gwynn, ${ }^{3}$ Tim Warren, ${ }^{4}$ Pritash Patel. ${ }^{1}$ Barts Health Nhs Trust, London, UK; ${ }^{2}$ Huddersfield Royal Infirmary, Huddersfield, UK; ${ }^{3}$ Triducive Ltd, Tunbridge Wells, UK; ${ }^{4}$ Epsom and St Hellers University Hospital NHS Trust, Epsom, UK

\subsection{6/gutjnl-2019-BSGAbstracts. 154}

Introduction Crohn's disease is an idiopathic chronic inflammatory bowel disease without a cure. About 50\% of Crohn's disease is progressive, leading to intestinal complications and surgery in about $30 \%$ of cases, 20 -years post-diagnosis.

Despite, existence of several guidelines, there are considerable variations in practice among practicing Gastroenterologist in the UK. In addition, the lack of reliable biomarkers prevent personalised treatment plans for complex cases of Crohn's disease, resulting in a degree of experimentation to establish therapeutic strategy.

This project aims to gain insight from practicing gastroenterologists around the UK regarding these issues, to review variation across the UK and offer appropriate recommendations.

Methodology This group met to consider the various issues affecting the clinical management of Crohn's disease and develop of a series of 40 consensus statements that could be tested by questionnaire.

Respondents were engaged by telephone contact and screened for their specialty and involvement with the prescribing of biologics. In order to achieve consensus with the wider group, a Delphi methodology was used.

The steering group predefined the threshold of agreement for consensus at $66 \%$ and over. Consensus was defined as 'high' at $\geq 66 \%$ and 'very high' at $\geq 90 \%$.

Results Fully completed questionnaires were received from 150 respondents.

Each response was coded as either agreement or disagreement, with 24 statements (60\%) exceeding the 66\% agreement threshold and 16 statements (40\%) failing to meet it.

Five statements (13\%) achieved agreement scores greater than $90 \%$ and indicated very strong consensus. Responses were received from across the UK, with the greatest number being from England. Clear variation was seen between respondents when the different localities were compared.

Discussion There are clear differences amongst respondent attitudes in London and other UK areas, including England.

All respondent groups strongly support the need for biologic therapy to be used first line for certain patient groups (83.3\% agreement).

All respondents support the assertion that the principles for switching between originator and biosimilar should be defined by gastroenterologists $(90.5 \%$ agreement $)$ and that patients should be consulted before being switched to a different biosimilar option (74\% agreement).

\section{PTH-096 FACTORS AFFECTING PATIENT DECISION- MAKING IN INFLAMMATORY BOWEL DISEASE (IBD) DYSPLASIA MANAGEMENT: A MIXED METHODS STUDY} ${ }^{1,2}$ Misha Kabir*, ${ }^{1,2}$ Siwan Thomas-Gibson, ${ }^{1,2}$ Ailsa Hart, ${ }^{1,2}$ Ana Wilson. 'St Mark's Hospital;
${ }^{2}$ Imperial College London

\subsection{6/gutjnl-2019-BSGAbstracts. 155}

Introduction Current literature suggests that IBD patients have high thresholds to accept a colectomy for colonic dysplasia, but in-depth qualitative analysis of the factors that affect their decision-making is lacking.

Methods 100 purposively sampled IBD patients completed free text answer questionnaires and 20 went on to partake in individual semi-structured interviews. $44 \%$ of the questionnaire participants and $70 \%$ of the interview participants had previously had dysplasia. Inductive framework thematic analysis was performed. Data saturation was achieved. 
Results Themes identified are summarised:

\section{Abstract PTH-096 Table 1}

\begin{tabular}{|c|c|}
\hline Themes & Sub-themes ( ${ }^{*}$ most frequently occurring themes) \\
\hline $\begin{array}{l}\text { Facilitators in shared } \\
\text { decision-making (SDM) } \\
\text { and decision confidence }\end{array}$ & $\begin{array}{l}\text { Feeling well informed: } \\
\text { - Give balanced \& accurate information* } \\
\text { - Explain all alternative options } \\
\text { - Address patient priorities: effect on quality of } \\
\text { life, family, career } \\
\text { - Allow time for independent research } \\
\text { - Personalised risk prediction allows rational } \\
\text { decision-making } \\
\text { - Joint medical/surgical clinics } \\
\text { Good relationship with clinical care team: } \\
\text { - Trust in experience \& peer consensus* } \\
\text { - Patient-centred \& supportive* } \\
\text { Address emotional and psychological wellbeing: } \\
\text { - Social media reduces stigma } \\
\text { - Positivity increases confidence } \\
\text { - Prepare for potential colectomy early } \\
\text { - Provide counselling and patient support network } \\
\text { Education may dispel fears (preferred formats: } \\
\text { patients, video, leaflet }\end{array}$ \\
\hline Barriers in SDM & $\begin{array}{l}\text { Suboptimal relationship with clinical team: } \\
\text { - Lack of options* } \\
\text { - Feeling rushed } \\
\text { - No continuity in care } \\
\text { - Not patient-centred } \\
\text { - Making wrong assumptions } \\
\text { Internet and social media can be unrealistic and } \\
\text { irrelevant } \\
\text { Avoidance of reality: } \\
\text { - Youthful naivety } \\
\text { - Over-optimism } \\
\text { - Fear }\end{array}$ \\
\hline $\begin{array}{l}\text { Reasons to accept } \\
\text { colectomy }\end{array}$ & $\begin{array}{l}\text { Dying from cancer is not an option* } \\
\text { Changing priorities with age } \\
\text { If segmental colectomy was an option } \\
\text { Reasons to accept a stoma: } \\
\text { - Allows more control } \\
\text { - Uncertainty about pouch function impact on } \\
\text { lifestyle } \\
\text { - More acceptable in older age } \\
\text { Reasons to accept a pouch } \\
\text { - It's closer to normality } \\
\text { - Can go back to stoma if it doesn't work }\end{array}$ \\
\hline $\begin{array}{l}\text { Reasons to decline } \\
\text { colectomy }\end{array}$ & $\begin{array}{l}\text { I feel fine, why risk my quality of life? } \\
\text { Surveillance is reassuring enough } \\
\text { Uncertainty in dysplasia prognosis } \\
\text { Negative patient stories } \\
\text { Concerns about stomas: } \\
\text { - Not normal } \\
\text { - Disrupts life } \\
\text { - Body image } \\
\text { - Leaks, smell and pain } \\
\text { Concerns about pouches: } \\
\text { - Pouch frequency disrupts life* } \\
\text { - Peri-operative complications } \\
\text { - Risk of cancer in pouch/cuff } \\
\text { Faith in alternative therapies and lifestyle changes } \\
\text { Fear of being a burden on family }\end{array}$ \\
\hline
\end{tabular}

Conclusions This is the first in-depth qualitative study to our knowledge exploring the barriers and facilitators for shared decision-making in IBD dysplasia management. These findings should guide clinicians to embrace a more patient-centred approach.

\section{PTH-097 DIETARY ANTIOXIDANTS AND THE RISK OF DEVELOPING ULCERATIVE COLITIS: A NESTED-CASE- CONTROL STUDY WITHIN EPIC-NORFOLK}

${ }^{1}$ James Kang* ${ }^{2}{ }^{2}$ Robert Luben, ${ }^{3}$ Andrew Hart. ${ }^{1}$ Norwich Medical School, University of East Anglia, Norwich, UK; ${ }^{2}$ Strangeways Research Laboratories, Cambridge, UK; ${ }^{3}$ Norwich Medical School, University of East Anglia, Norwich, UK

\subsection{6/gutjnl-2019-BSGAbstracts.156}

Introduction Oxidative stress may be involved in ulcerative colitis (UC) aetiology. Here we investigate, for the first time using a prospective study design, whether the dietary antioxidants vitamins $\mathrm{C}, \mathrm{E}$ and zinc are associated with a decreased risk of developing UC, using 7-day food diaries, the most accurate dietary methodology.

Methods A cohort of 23,658 participants, aged 40-74 years, enrolled in the European Prospective Investigation of CancerNorfolk between 1993-1997. At recruitment participants completed 7-day food diaries that recorded food intake including frequency, brands and portion sizes. Nutrient intakes were computed using a specifically designed nutrient database of 11,000 food items. The cohort was monitored to 2004 to identify incident UC cases. Conditional logistic regression analysis calculated odds ratios (OR) of developing UC across tertiles of intake. Adjustments were made for smoking status and energy intake.

Results During follow-up 26 individuals (42\% female) developed UC, 35\% of whom had left-sided disease. Multivariable analyses showed no associations between any of vitamin C, vitamin $\mathrm{E}$ and zinc and the odds of $\mathrm{UC}$, with no trends across tertiles (For vitamin C: 3 rd vs 1 st tertile $\mathrm{OR}=2.03$, $95 \%$ confidence interval $(\mathrm{CI})=0.67-6.20$; trend $\mathrm{OR}=1.42$, 95\% CI $=0.82-2.45$; For vitamin $\mathrm{E} 3 \mathrm{rd}$ vs 1 st tertile $\mathrm{OR}=1.04, \quad 95 \% \quad \mathrm{CI}=0.27-4.07 ; \quad$ trend $\mathrm{OR}=1.10, \quad 95 \%$ $\mathrm{CI}=0.57-2.14$; For zinc $3 \mathrm{rd}$ vs 1 st tertile $\mathrm{OR}=2.00$, 95\% $\mathrm{CI}=0.42-9.53$; trend $\mathrm{OR}=1.38,95 \% \mathrm{CI}=0.69-2.78$ ).

Conclusions The data does not support a role for any of vitamin $\mathrm{C}$, vitamin $\mathrm{E}$ and zinc in preventing UC. Further followup of the cohort is continuing to make estimates with better precision.

\section{PTH-098 MINIMALLY INVASIVE ENDOSCOPIC APPROACHES TO MANAGE COMPLICATED IBD PATIENTS AT A TERTIARY CARE CENTER}

${ }^{1}$ Ikwinder Kaur*, 1,2Prabh Singh, 'Alyssa Meyer, 'Zaheer Rizvi, 'Victor Chedid, ${ }^{1}$ Kevin Quinn, ${ }^{1}$ Navtej Buttar. ${ }^{1}$ Mayo Clinic, Rochester, USA; ${ }^{2}$ Government Medical College and Hospital, Chandigarh, India

\subsection{6/gutjnl-2019-BSGAbstracts.157}

Introduction Patients with complicated IBD have a higher risk of recurrent surgeries, prolonged hospitalizations, morbidity and mortality. We aim to review endoscopic stenting for management of strictures and/or fistula as primary or rescue interventions in these complicated IBD patients. 